\title{
Brain behind bars. The relationship between neurobiological factors and cognitive skills training program for prisoners
}

\author{
Josanne van Dongen
}

Cornet, L. (2015). Brain behind bars. The relationship between neurobiological factors and cognitive skills training program for prisoners (dissertatie VU Amsterdam).

$\mathrm{Na}$ de affaire Buikhuisen in de jaren tachtig (hij werd verguisd omdat hij een biologische kijk op crimineel gedrag opperde) is er weer hernieuwde aandacht voor de biologische criminologie. Het proefschrift van Cornet is een welkome aanvulling op de reeds bestaande literatuur over de relatie tussen (neuro)biologie en crimineel gedrag. Daarin bestudeert zij namelijk niet alleen de relatie tussen neurobiologische factoren en een trainingsprogramma voor cognitieve vaardigheden ( $\mathrm{CoVa}$ ) voor volwassen gedetineerden, maar ook waarom de ene gedetineerde persoon wel, en de andere gedetineerde persoon geen baat lijkt te hebben bij bepaalde interventies zoals de CoVa.

Nadat Cornet in hoofdstuk 1 een algemene inleiding heeft gegeven, start het onderzoek in hoofdstuk 2 met een literatuuroverzicht. Dit hoofdstuk geeft een overzicht van neurobiologische factoren als voorspellers van de effectiviteit van cognitieve gedragstherapie (CGT) in personen met antisociaal gedrag. Hieruit bleek dat een bepaalde mate van stress, bijvoorbeeld gemeten met psychofysiologie, voorspellend kan zijn voor behandelsucces.

In hoofdstuk 3 worden de uitkomsten van het empirische onderzoek besproken en wordt zodoende verder ingegaan op de rol van neurobiologische veranderingen in behandeleffectiviteit. In het onderzoek worden specifiek de rol van een lage hartslag en ook het functioneren op neurocognitieve tests in relatie tot behandeluitkomsten onderzocht. Uit de resultaten van de studie bleek dat het presteren op een neurocognitieve taak die concentratie meet een betere voorspeller was voor uitval in het behandeltraject dan gedragsuitkomsten en zelfgerapporteerde motivatie.

In hoofdstuk 4 wordt wederom aan de hand van een literatuurstudie gekeken naar veranderingen in neurobiologische kenmerken als gevolg van interventie. Er werden elf studies in het overzicht opgenomen, waarvan echter maar één studie een steekproef van volwassenen heeft bekeken. De overige studies hadden kinderen en/of adolescenten geïncludeerd. Uit de literatuurstudie bleek dat bepaalde neurobiologische factoren, zoals het niveau van het hormoon cortisol, kunnen veranderen door interventie en tevens gerelateerd zijn aan gedragsveranderingen. Dat interventies niet altijd leiden tot veranderingen in neurobiologische factoren wordt aangetoond in hoofdstuk 5 van het proefschrift. In dat hoofdstuk worden 
aanvullende uitkomsten van de eerder beschreven empirische studie gepresenteerd. Doel van de studie was om te onderzoeken in hoeverre deelname aan een CoVa-training leidt tot veranderingen in neurobiologische factoren (i.e. hartslag). Uit deze studie bleek dat er geen veranderingen optraden in hartslag, en ook niet in de uitkomsten op neurocognitieve taken nadat de gevangenen een CoVa-training hadden gevolgd. Niet alleen liet deze studie zien dat de verwachte veranderingen op neurobiologisch gebied uitbleven, ook werd geen verbetering in gedrag gevonden, zoals bijvoorbeeld gemeten met een schaal die sociaal gedrag en agressie meet.

In hoofdstuk 6 wordt vervolgens beschreven hoe inzichten vanuit neurowetenschappelijk onderzoek zouden kunnen bijdragen aan onderzoek binnen het criminologische werkveld. Cornet beschrijft hierin vooral de toegevoegde waarde van het bepalen van de hartslag, een psychofysiologische maat, en het gebruik van neuropsychologische assessmentprocedures.

Een algemene discussie wordt door Cornet gehouden in hoofdstuk 7 van het proefschrift. Geconcludeerd wordt dat alleen aanwijzingen werden gevonden voor de relatie tussen veranderingen in neuropsychologische variabelen en behandeluitkomsten en gedragsverandering in de literatuurstudie. Het empirische onderzoek leverde helaas geen bewijs voor de effectiviteit van de CoVa of veranderingen in neuropsychologische factoren tot die effectiviteit. Deze conclusie komt overeen met het onderzoek van Verweij e.a. (2016), die aantoonden dat er beperkte aanwijzingen zijn voor de effectiviteit van de CoVa in het reduceren van recidive.

Bij het lezen van het proefschrift van Cornet viel mij een aantal zaken op. Deze punten zal ik hier uiteenzetten. Ten eerste is het theoretische kader waarop het werk van Cornet is gebaseerd, het What Works-principe (Andrews, 1995), een erg interessante benadering, die ook handvatten kan bieden voor het optimaliseren van interventies binnen het gevangeniswezen en de justitiële setting in het algemeen. Hierin gaat men ervan uit dat een persoon te behandelen is als bepaalde interventies goed aansluiten (responsivity) op de criminogene factoren (needs) van een persoon (Risk-Need-Responsivity Model; Andrews e.a., 1990). De behandelinterventie zal dus daadwerkelijk effectief zijn voor de gedetineerde persoon wanneer de interventie aansluit bij de specifieke criminogene behoeften van die gedetineerde. Daarmee zal ook het recidiverisico verminderen. Met de hierboven genoemde insteek raakt Cornet een belangrijk punt. In de geestelijke gezondheidszorg, zo ook binnen de correctionele setting, is het gangbaar om personen psychologisch en psychiatrisch te beoordelen aan de hand van overt gedrag. Zo wordt men op basis van bepaalde 'symptomen' ingedeeld in categorieën (bijvoorbeeld van bepaalde geestelijke stoornissen volgens de DSM-V). De behandeling wordt vervolgens op die classificatie toegesneden. Uit onderzoek blijkt echter dat wellicht een indeling die gebaseerd is op biocognitieve factoren van verschillende niveaus effectiever is, omdat het nodig is dat interventies aansluiten op latente (onderliggende) biocognitieve mechanismen (Brazil e.a., 2016). Het principe dat de (gedetineerde) persoon 'vatbaar' (responsivity-principe) moet zijn voor een behandeling die is toegesneden op de needs, wordt op die manier veel effectiever nageleefd. 
Ten tweede wordt in het overzichtsartikel over neurobiologische voorspellers van effectiviteit van CGT, dat beschreven staat in hoofdstuk 2, vooral ingegaan op de lagere arousal-waarden gemeten door middel van de hartslag en het stresshormoon cortisol, vooral bij kinderen en jongeren. De studie geeft ondersteuning voor de low arousal-theorie (zie Ortiz \& Raine, 2004). Echter, ook wordt gevonden dat juist een hogere cortisolreactiviteit op stressvolle gebeurtenissen te zien is bij een bepaalde groep volwassenen met antisociaal gedrag (Fishbein e.a., 2009). In het kort lijkt de conclusie dat personen (volwassenen en kinderen) met een hogere mate van opwinding (bijvoorbeeld een hogere hartslag in rust) een meer positieve uitkomst van de behandeling hebben dan personen die een verlaagde reactie laten zien. Deze uitkomsten worden geïnterpreteerd in het licht van het idee van Mangina en Beuzeron-Mangina (1992), dat leren optimaal plaatsvindt bij bepaalde niveaus van opwinding. Het feit dat opwinding bij individuen met antisociaal gedrag vaak suboptimaal is, kan verklaren waarom deze personen niet zoveel baat hebben bij bijvoorbeeld CGT. Overigens komt deze gedachte ook overeen met het idee van Blair (Blair, 1995; Blair e.a., 2005; Mitchell \& Blair, 2005), dat personen met antisociaal gedrag en een psychopathische persoonlijkheid niet optimaal fysiologisch reageren op negatieve uitkomsten van hun gedrag, zoals angst bij een slachtoffer. Het uitblijven van hogere arousal in reactie op deze negatieve consequenties (een vorm van empathie), kan leiden tot het niet leren/aanpassen van het gedrag. Dit heeft te maken met het disfunctioneren van onder andere de amygdala (maar ook delen van de prefrontale cortex) in personen met psychopathische eigenschappen, maar hier wordt in hoofdstuk 2 helaas niet op ingegaan.

Ten derde, de hierboven beschreven hypothese, dat personen met antisociaal gedrag minder goed vaardigheden kunnen aanleren, sluit aan bij de aanbeveling van Cornet, dat personen die niet optimaal reageren op CGT meer baat zouden kunnen hebben bij een neurobiologisch georiënteerde behandeling. Hierin durf ik nog een stapje verder te gaan door te stellen dat uit onderzoek is gebleken dat voor sommige stoornissen, zo ook gerelateerd aan crimineel gedrag, transcranial direct current stimulation ( $\mathrm{DDCS}$ ) een veelbelovende nieuwe behandelmethode is (Fecteau e.a., 2007; Riva e.a., 2014; Van Outsem, 2011). Het idee achter tDCS is dat het de hersenen meer vatbaar maakt voor leren, en daarom zal deze methode wellicht in de toekomst in combinatie met CGT kunnen worden aangeboden. De functionele (en wellicht structurele) dysfuncties in de hersenen bij personen met antisociaal gedrag kunnen door het moduleren van de hersenfunctionaliteit door tDCS weer beter functioneren, waardoor CGT beter zal aanslaan bij deze personen. In de praktijk zou dit veel voordelen op kunnen leveren. Nu wordt als er sprake is van ernstige psychische problematiek vaak een combinatie van medicatie en CGT aangeboden, maar omdat medicatie veel bijwerkingen heeft, is de medicatieontrouw helaas vrij hoog. tDCS is een niet-invasieve methode en heeft voor zover bekend nagenoeg geen bijwerkingen (Brunoni e.a., 2011). Dit maakt deze nieuwe neurobiologische vorm van behandeling een aantrekkelijk en veelbelovend alternatief voor medicatie.

Ten vierde wordt er in hoofdstuk 3 ook besproken dat eerder onderzoek laat zien dat CGT niet alleen op gedragsniveau, maar ook op neuraal niveau veranderingen 
teweeg lijkt te brengen. Deze veranderingen in de hersenen lijken ook weer te zorgen voor veranderingen op gedragsniveau (zie Vaske e.a., 2011). Zo wordt gesteld dat een belangrijk domein van vaardigheden binnen CGT het verbeteren van cognitieve en affectieve empathie is. Deze vaardigheden blijken gerelateerd te zijn aan bepaalde gebieden in de hersenen, zoals de ventromediale prefrontale cortex (vmPFC) en de temporoparietal junction (zie Decety 2011; Lamm e.a., 2011). De neurobiologische componenten (in dit geval gerelateerde hersenstructuren) die aangesproken worden door CGT kunnen dus ook als indicatie dienen om te beoordelen of personen naar verwachting positief zullen reageren op behandeling met CGT. Dit punt, tevens benadrukt in de algemene discussie van de dissertatie (p. 193), is belangrijk en geeft meteen ook aan dat het cruciaal is bepaalde processen zo gedetailleerd mogelijk te onderzoeken. Zo wordt in het proefschrift bijvoorbeeld besproken dat CGT (inclusief CoVa-training) zich richt op het verbeteren van het cognitief empathische vermogen, omdat dit gerelateerd blijkt te zijn aan antisociaal gedrag (Jolliffe \& Farrington, 2004). Echter, naar mijn beste weten blijkt uit het merendeel van empirisch onderzoek dat juist cognitieve aspecten van empathie intact zijn bij personen met psychopathische eigenschappen (die verantwoordelijk zijn voor de meest gewelddadige misdrijven), terwijl affectieve aspecten van empathie verminderd zijn in die personen (zie o.a. Van Dongen, ingediend). Meer inzicht in de precieze neurobiologische mechanismen van specifieke aspecten van aan te leren vaardigheden binnen CGT en CoVa is zeer belangrijk voor de behandeleffectiviteit van deze trainingen en daarmee ook voor het verminderen van recidive binnen de justitiële setting.

Als laatste is het belangrijk te bespreken dat in het proefschrift van Cornet vooral 'eenvoudige' processen, zoals die van een lage arousal en dysfunctie van geïsoleerde gebieden in de hersenen, verklaringen voor crimineel gedrag en behandeleffectiviteit lijken te vormen. Uit recente onderzoeken blijkt echter dat verschillende eigenschappen binnen antisociaal gedrag gerelateerd zijn aan fysiologische over- of onder-arousal (Fanti, 2016; Fanti e.a., 2017). Ook is gebleken dat niet vooral de prefrontale cortex, maar ook andere gebieden in de hersenen een zeer belangrijke rol spelen in antisociaal en crimineel gedrag (Carré e.a., 2013). Recent wordt zelfs gesproken van breinnetwerken die gerelateerd zijn aan antisociaal gedrag en/of psychopathische persoonlijkheid (zie Tillem e.a., in revisie). Juist door de complexiteit van mechanismen die onderliggend zijn aan antisociaal en crimineel gedrag is het zo belangrijk om antisociaal gedrag te begrijpen vanuit meerdere niveaus van biocognitief functioneren (Brazil e.a., 2016). Vaak ligt er een ingewikkeld neurobiologisch proces aan ten grondslag, dat niet in een een-opeenassociatie kan worden aangetoond. Uit recent onderzoek blijkt bijvoorbeeld dat verschillende onderliggende genetische predisposities interacteren met andere (omgevings)factoren en niet in alle groepen van personen met antisociaal gedrag gerelateerd zijn aan hun gedrag. Zo toonden Van Dongen e.a. (2017) in een recent gepubliceerd onderzoek aan dat het Val-allel van het COMT-gen aan agressie is gerelateerd en dat deze relatie gemedieerd wordt door disinhibitie (i.e. impulsiviteit), maar alleen in een groep gevangenen met een psychotische stoornis, en niet in gevangenen die een persoonlijkheidsstoornis hebben. 
Samengevat kan gesteld worden dat het proefschrift van Cornet een welkome aanvulling is op de reeds bestaande literatuur aangaande de rol van neurobiologische factoren in het optimaliseren van de behandeling van gedetineerden. Een aanbeveling is echter om naast de rol van hartslag als psychofysiologische maat en neuropsychologisch assessment ook mechanismen op neuraal niveau mee te nemen in onderzoek, zodat daadwerkelijk uitspraken over de rol van neurowetenschappelijke inzichten in relatie tot behandeluitkomsten in CGT gedaan kunnen worden. Deze inzichten kunnen de effectiviteit van CoVa-training verbeteren en ook handvatten bieden voor het laten aansluiten van modules op de individuele needs van de gedetineerde persoon. Door gedetineerden te classificeren op basis van groepen latente variabelen (bijvoorbeeld neurobiologische mechanismen, zie Brazil e.a., 2016) kunnen de modules van de CoVa, gericht op specifieke dysfunctionele vaardigheden (needs), toegesneden worden op de behoeften van de gedetineerde persoon, waardoor de behandeleffectiviteit (responsivity) toeneemt en het recidiverisico afneemt.

\section{Literatuur}

Andrews, D. (1995). The psychology of criminal conduct and effective treatment. In: J. McGuire (ed.). What Works: reducing reoffending. Guidelines from research and practice. Chester: Wiley, 35-62.

Andrews, D.A., Bonta, J. \& Hoge, R.D. (1990). Classification for effective rehabilitation: rediscovering psychology. Criminal Justice and Behavior, 17(1), 19-52.

Blair, R.J.R. (1995). A cognitive developmental approach to morality: investigating the psychopath. Cognition, 57(1), 1-29.

Blair, J., Mitchell, D. \& Blair, K. (2005). The psychopath: emotion and the brain. Blackwell Publishing.

Brazil, I.A., Dongen, J.D.M. van, Maes, J.H.R., Mars, R.B. \& Baskin-Sommers, A.R. (2016). Classification and treatment of antisocial individuals: from behavior to biocognition. Neuroscience \& Biobehavioral Reviews.

Brunoni, A.R., Amadera, J., Berbel, B., Volz, M.S., Rizzerio, B.G. \& Fregni, F. (2011). A systematic review on reporting and assessment of adverse effects associated with transcranial direct current stimulation. International Journal of Neuropsychopharmacology, 14(8), 1133-1145.

Carré, J.M., Hyde, L.W., Neumann, C.S., Viding, E. \& Hariri, A.R. (2013). The neural signatures of distinct psychopathic traits. Social Neuroscience, 8(2), 122-135.

Decety, J. (2011). Dissecting the neural mechanisms mediating empathy. Emotion Review, 3(1), 92-108.

Dongen, J.D.M. van, Schaik, R.H.N. van, Fessem, M. van \& Marle, H.J.C. van (2017). Association between the COMT Val158Met polymorphism and aggression in a forensic inpatient sample. Psychology of Violence. Advance online publication. doi: 10.1037/ vio0000119.

Fecteau, S., Knoch, D., Fregni, F., Sultani, N., Boggio, P. \& Pascual-Leone, A. (2007). Diminishing risk-taking behavior by modulating activity in the prefrontal cortex: a direct current stimulation study. Journal of Neuroscience, 27(46), 12500-12505.

Fishbein, D., Sheppard, M., Hyde, C., Hubal, R., Newlin, D., Serin, R. e.a. (2009). Deficits in behavioral inhibition predict treatment engagement in prison inmates. Law and Human Behavior, 33(5), 419-435. 
Lamm, C., Decety, J. \& Singer, T. (2011). Meta-analytic evidence for common and distinct neural networks associated with directly experienced pain and empathy for pain. Neuroimage, 54(3), 2492-2502.

Mangina, C.A. \& Beuzeron-Mangina, J.H. (1992). Psychophysiological treatment for learning disabilities: controlled research and evidence. International Journal of Psychophysiology, 12(3), 243-250.

Ortiz, J. \& Raine, A. (2004). Heart rate level and antisocial behavior in children and adolescents: a meta-analysis. Journal of the American Academy of Child \& Adolescent Psychiatry, 43(2), 154-162.

Outsem, R. van (2011). The applicability of neurofeedback in forensic psychotherapy: a literature review. Journal of Forensic Psychiatry \& Psychology, 22(2), 223-242.

Riva, P., Romero Lauro, L.J., DeWall, C.N., Chester, D.S. \& Bushman, B.J. (2014). Reducing aggressive responses to social exclusion using transcranial direct current stimulation. Social Cognitive and Affective Neuroscience, 10(3), 352-356.

Tillem, S., Dongen, J.D.M. van, Brazil, I.A. \& Baskin-Sommers, A. (in revisie). Psychopathic traits are differentially associated with efficiency of neural communication. Psychophysiology.

Vaske, J., Galyean, K. \& Cullen, F.T. (2011). Toward a biosocial theory of offender rehabilitation: why does cognitive-behavioral therapy work? Journal of Criminal Justice, 39(1), 90-102.

Wium-Andersen, I.K., Vinberg, M., Kessing, L.V. \& McIntyre, R.S. (2017). Personalized medicine in psychiatry. Nordic Journal of Psychiatry, 71(1), 12-19. 
Reproduced with permission of copyright owner. Further reproduction prohibited without permission. 